\title{
ESTUDO DA ASSISTÊNCIA DE ENFERMAGEM A CRIANÇAS QUE APRESENTAM SÍNDROME DE DOWN
}

Wendy Ann Carswell*

O diagnóstico de Síndrome de Down pode ser feito em berçário. A presença da criança atípica leva a desagregação da família. A intervenção da enfermeira ensinando técnicas higiênicas, alimentares e de estimulação precoce poderá permitir um ajuste melhor da família.

O estudo de dez crianças com Síndrome de Down e seus familiares, realizado num período de seis anos, demonstrou que o diagnóstico precoce da afecção permite que se inicie precocemente a estimulação da criança, assim como a orientação do casal. A estimulação tardia leva a resultados menos favoráveis assim como à maior dificuldade de adaptação da criança à família.

UNITERMOS: Criança atípica, atípica, desempenhar, vínculo afetivo, Síndrome de Down.

\section{Introdução}

A primeira descrição clínica da síndrome, provavelmente foi feita por EDVARD SEGUIN ${ }^{22}$ entre 1846 e 1866. Com a publicação do trabalho "Observations of an ethnic classification of idiots", em 1866, LANGDON DOWN ${ }^{8}$ considerou como sua hipótese básica, que as crianças seriam resultado de uma possível degeneração da raça superior caucasiana a uma raça inferior mongólica. Daí o nome mongolismo.

Somente em 1959 foi comprovado a causa genética de mongolismo por três cientistas franceses, LEJEUNE, TURPIN e GAUTIER ${ }^{17}$ ao demonstrarem a existência de um cariótipo com um cromossomo a mais, identificando-se a chamada trissomia 21. Outros trabalhos

*Professora Doutora do Departamento de Enfermagem das Faculdades Barão de Mauá. 
citogenéticos revelaram diferentes aberrações cromossômicas associadas a essa entidade clínica, representadas por translocações e isocromossos $21^{19}$.

A partir de 1948 associações para crianças retardadas começaram a ser fundadas e, em 1962, o presidente John F. Kennedy com a convocação de "Blue Ribbon Panel" sobre retardamento mental estimulou o reexame do problema e a procura de meios, mais humanitários, para sua solução.

A incidência da Síndrome de Down na população geral é de um para cada 600 nascimentos ${ }^{3}$. Estudos realizados em Ribeirão Preto (SP), relatam uma incidência de 1,7 por 1000 nascimentos $^{26}$ e de 1,2 por 1000 nascimentos $^{18}$.

Dados colhidos pelo Departamento de Genética da Faculdade de Medicina de Ribeirão Preto, USP, nos últimos 10 anos indicam que foram atendidos em média 300 casos novos por ano, sendo que mais de 60\% dos casos (aproximadamente 180 pacientes) apresentam deficiência mental de graus variáveis. Dessas 30\% são portadores da Síndrome de Down. A procedência da quase totalidade (92\%) destes pacientes foi do Estado de São Paulo; $0,8 \%$ de Goiás; $0,4 \%$ de Mato Grosso; $6,7 \%$ de Minas Gerais e $0,1 \%$ de outros Estados.

Durante nossas atividades diárias como profissionais de enfermagem em hospitais locais, observamos os problemas comumente enfrentados pelas famílias ao nascer uma criança Down, principalmente a angústia, sentimentos de culpa, e a procura de justificativa, que acarretavam um processo de desequilíbrio familiar. O desespero dos familiares e a ausência de uma assistência imediata disponível despertaram interesse nestas crianças e estimulou o estudo do problema.

Diante do exposto propusemo-nos a realizar treinamento precoce das crianças com diagnóstico de Síndrome de Down dos hospitais locais, dos serviços de pediatria e do Departamento de Genética da Faculdade de Medicina de Ribeirão Preto, com a finalidade de:

a) ajudar a criança a desenvolver hábitos básicos da vida diária;

b) favorecer a manutenção da estrutura familiar através do controle da ansiedade dos pais e orientação sobre como integrar a criança na família.

\section{Metodologia}

\section{População}

Das 150 crianças encaminhadas por hospitais locais, serviços de pediatria e pelo Departamento de Genética da Faculdade de Medicina de Ribeirão Preto da Universidade de São Paulo (FMRP-USP), foram selecionadas para estudo, 10 famílias que apresentavam uma única criança com Síndrome de Down e com maior freqüência ao atendimento. 


\section{Procedimento}

Para a colheita dos dados foram utilizados basicamente, a observação-participação (para interação e avaliação da criança). Com a família utilizamos a entrevista face a face, sistematizada "a priori" com intuito de conscientizar os familiares quanto aos problemas da criança, orientação dos pais quanto a estimulação precoce da criança e sua adaptação no contexto. Em seguida, foram usadas fichas para coletar os dados necessários para o estudo do caso e treinamento a ser executado em casa.

O processo de estimulação precoce e treinamento prosseguiram da seguinte maneira:

1) anotações de dados relevantes quanto a gestação, o parto, as condições da criança ao nascer para conhecer ou eliminar outros fatores que poderiam causar maior retardo no desenvolvimento físico e mental da criança;

2) concomitantemente, foi feita uma orientação aos pais, quanto a Síndrome e seu efeito no potencial da criança Down;

3) coleta de dados quanto ao entrosamento da criança na família, rotina diária, o ambiente, estímulos disponíveis, amamentação, vacinação e cuidados gerais;

4) o desempenho da criança foi avaliado frente aos estímulos fornecidos com brinquedos pedagógicos, sons e exercícios. Fez-se a avaliação de sua adaptação ao ambiente, observando-se suas reações, sua linguagem e dependência utilizando consulta e comparação com tabelas de desenvolvimento infantil normal;

5) Os programas das atividades a serem desenvolvidas com a criança, em casa, envolveu serviços físicos, de linguagem, estimulação de coordenação e de outras habilidades motoras e sociais seguindo as tabelas de desenvolvimento Infantil $\operatorname{Normal}(25,2,14,23,24)$ e o Programa de Estimulação da Criança de um mês do Children's Hospital of Washington DC ${ }^{20}$. Através das lacunas encontradas entre a idade, o estímulo e o desempenho da criança, a programação foi elaborada e ensinada a família.

Ao mesmo tempo, os pais e os demais membros da família eram observados e avaliados durante entrevistas e suas interações com a criança Down, quanto ao estado de ansiedade, sentimentos de culpa, não aceitação ou negação do problema. Encaminhamentos e consultas psiquiátricas feitos quando necessários;

6) fornecimento a família de uma ficha de desenvolvimento normal de uma criança, um caderno de exercícios para crianças hipotônicas de zero a nove meses, programas de atividades de estimulação precoce individualizados, a data e a hora do próximo retorno.

O seguimento das crianças e familiares foi realizado em salas montadas especificamente para este trabalho, numa casa, no centro da cidade, alugada pelo Convenio de Saúde Mental da Escola de Enfermagem de Ribeirão Preto - USP, junto a Coordenadoria de Saúde Mental do Estado de São Paulo. 


\section{Tempo de treinamento}

O tempo médio utilizado na entrevista inicial foi de noventa a cento e vinte minutos. Nas entrevistas (retornos eram marcados conforme distância da moradia do paciente, local semanalmente, outras cidades - quinzenalmente e outros estados - mensalmente) subseqüentes o tempo gasto variou entre quarenta e cinco a sessenta e noventa minutos, conforme as seguintes variáveis:

a) idade da criança - quanto maior for a idade, major e o tempo dispendido;

b) presença da família para exposição das dificuldades, esclarecimento de dúvidas, preocupações ou problemas que necessitam encaminhamento (solicitação de colaboração de outros colegas ou profissionais);

c) cansaço apresentado pela criança, principalmente as que possuem cardiopatias.

\section{Resultados}

As crianças selecionadas para este estudo pertenciam a dez famílias que possuíam uma única criança portadora da Síndrome de Down, sendo 4 destas crianças masculinas e 6 femininas.

A Tabela 1 apresenta as seguintes variáveis da população Down em estudo: sexo, cariótipo, posição hierárquica de nascimento, tipo de aleitamento e doenças congênitas.

Dos 10 casos selecionados 7 crianças (FCM, MAP, MB, CAFN, ECF, RAS, SRC) foram amamentados no seio materno, sendo 4 (FCM, MAP, ECF, RAS) destas com a ajuda de suplementação artificial; as outras 3 crianças (AAW, ACPG, SMM) foram exclusivamente amamentadas artificialmente, SMM apresentou intolerância ao leite de vaca, tendo sido alimentado com leite de soja.

Todas as crianças eram portadoras de trissomia do cromossomo 21 por não disjunção e 3 (FCM, MAP e ECF), tinham cardiopatias congênitas. O número de filhos em cada família estudada era variável, mas em quatro (FCM, MB, ACPG, SRC) o afetado era o primeiro filho sendo que destas, em duas (ACPG e SRC), era o único filho. 
TABELA 1 - Paralelos das 10 crianças Down estudadas em relação ao sexo, cariótipo, ordem de nascimento, alimentação e doenças

\begin{tabular}{|c|c|c|c|c|c||}
\hline $\begin{array}{c}\text { Identif. da } \\
\text { Criança* }\end{array}$ & Sexo & Cariótipo & $\begin{array}{c}\text { Ordem de } \\
\text { Nascimento }\end{array}$ & $\begin{array}{c}\text { Tipo de } \\
\text { Aleitamento }\end{array}$ & $\begin{array}{c}\text { Doenças } \\
\text { Congênitas }\end{array}$ \\
\hline FCM & $\mathrm{M}$ & $47 \mathrm{XY}+\mathrm{G}$ & 1 filho & Misto LM/LA & Cardiopatia \\
\hline MAP & $\mathrm{M}$ & $47 \mathrm{XY}+\mathrm{G}$ & 10 filho & Misto LM/LA & Cardiopatia \\
\hline MB & $\mathrm{M}$ & $47 \mathrm{XY}+\mathrm{G}$ & 1 filho & LM & - \\
\hline AAW & $\mathrm{F}$ & $47 \mathrm{XX}+\mathrm{G}$ & 3 filho & LM & - \\
\hline CAFN & $\mathrm{F}$ & $47 \mathrm{XX}+\mathrm{G}$ & 2 filho & LA & Cardiopatia \\
\hline ACPG & $\mathrm{M}$ & $47 \mathrm{XY}+\mathrm{G}$ & 1 filho & Misto LM/LA & - \\
\hline ECF & $\mathrm{F}$ & $47 \mathrm{XX}+\mathrm{G}$ & 4 filho & Misto LM/LA & Intolerância a \\
\hline RAS & $\mathrm{F}$ & $47 \mathrm{XX}+\mathrm{G}$ & 4 filho & Leite de vaca \\
\hline Infec. Intest.
\end{tabular}

*Identificação da criança

As idades dos pais, ao nascimento do filho atípico mostradas na Tabela 2, variam entre 21 e 47 anos sendo que 5 mães apresentavam uma idade superior a 30 anos, duas com idade acima de 35 anos e sete pais com mais de 30 anos, sendo três acima de 35 anos. A idade materna mais avançada era de 42 anos e a menor de 21 anos. O pai mais velho tinha 47 anos e o mais novo 23 anos.

A escolaridade dos pais diversificou entre o analfabetismo e o nível superior. Dois casais e um pai tinham escolaridade de primeiro grau completo, 3 casais e uma mãe tinha primeiro grau incompleto, 3 pessoas eram analfabetas, um casal e uma mãe tinham o curso de segundo grau completo e um casal o curso superior (Tabela 2). 
TABELA 2 - Idade dos pais ao nascer a criança Down e a sua escolaridade

\begin{tabular}{|c|c|c|c|c|}
\hline \multirow{2}{*}{$\begin{array}{c}\text { Identificação da } \\
\text { Família Através } \\
\text { da Criança }\end{array}$} & \multicolumn{2}{|c|}{$\begin{array}{c}\text { Idade dos pais ao nascer } \\
\text { criança Down }\end{array}$} & \multicolumn{2}{|c|}{ Escolaridade } \\
\hline & Mãe & Pai & Mãe & Pai \\
\hline FCM & 21 & 23 & $2^{\circ}$ grau & $2^{\circ}$ grau \\
\hline MAP & 42 & 47 & $3^{a}$ série & $3^{\mathrm{a}}$ série \\
\hline $\mathrm{MB}$ & 26 & 27 & $3^{a}$ série & $3^{a}$ série \\
\hline AAW & 29 & 31 & $2^{\circ}$ grau & $1^{\circ}$ grau \\
\hline CAFN & 29 & 39 & $4^{\mathrm{a}}$ série & $4^{\mathrm{a}}$ série \\
\hline ACPG & 30 & 33 & $4^{a}$ série & $4^{\mathrm{a}}$ série \\
\hline ECF & 40 & 47 & Analfab. & Analfab. \\
\hline RAS & 34 & 39 & $3^{a}$ série & Analfab. \\
\hline SMM & 29 & 30 & $3^{\circ}$ grau & $3^{\circ}$ grau \\
\hline SRC & 35 & 27 & $1^{\mathrm{a}}$ série & $3^{a}$ série \\
\hline
\end{tabular}

LA = leite artificial

$\mathrm{LM}=$ leite materno

Verifica-se que as idades das crianças encaminhadas para estudo (Tabela 3), variaram desde 2 meses e meio até 5 anos e meio. Quatro crianças apresentavam idades inferiores a 1 ano e, de seis que apresentavam idades maiores do que 1 ano, quatro tinham acima de 3 anos.

A Tabela 3 apresenta a avaliação do desempenho da criança durante diferentes tempos de estimulação. Observa-se que FCM, MAP, MB e SMM, que iniciaram o treinamento mais precocemente, atingiram mais cedo estágios mais avançados de desenvolvimento. 
TABELA 3 - tabela comparativa dos 10 casos estudados de idades ao iniciar e terminar o período total de estimulação, desempenho alcançado

\begin{tabular}{|c|c|c|c|c||}
\hline Identificação & $\begin{array}{c}\text { Idade Inicial da } \\
\text { Estimulação }\end{array}$ & $\begin{array}{c}\text { Idade da Fase } \\
\text { Atual de } \\
\text { Estimulação }\end{array}$ & $\begin{array}{c}\text { Período Total de } \\
\text { Estimulação }\end{array}$ & $\begin{array}{c}\text { Desempenho } \\
\text { Alcançado }\end{array}$ \\
\hline FCM & $3 m$ & $3 a$ e $3 m$ & $3 a$ e $7 m$ & $3 a$ \\
\hline MAP & $4 m$ & $3 a$ e $8 m$ & $3 a$ e $4 m$ & $3 a$ e 3-6m \\
\hline MB & $2 m$ & $4 a$ e $5 m$ & $4 a$ e $3 m$ & $3 a$ e $6 m$ \\
\hline AAW & $4 a$ e $3 m$ & $7 a$ e $7 m$ & $3 a$ e $4 m$ & $4 a$ \\
\hline CAFN & $2 a$ e $4 m$ & $5 a$ e $7 m$ & $3 a$ e $3 m$ & $3 a$ e $7 m$ \\
\hline ACPG & $3 a$ e $1 m$ & $9 a$ e $3 m$ & $6 a$ e $2 m$ & $4 a$ \\
\hline ECF & $4 a$ e $5 m$ & $9 a$ & $4 a$ e $7 m$ & $4 a$ \\
\hline RAS & $1 a$ e $3 m$ & $5 a$ e $10 m$ & $4 a$ e $7 m$ & $3^{a}$ \\
\hline SMM & $5 m$ & $5 a$ e $2 m$ & $4 a$ e $9 m$ & $4 a$ e $6 m$ \\
\hline SRC & $5 a$ e $6 m$ & $9 a$ e $6 m$ & $4 a$ & $4 a$ \\
\hline
\end{tabular}

TABELA 4 - Adaptação à família, super proteção e aceitação do problema pelos pais

\begin{tabular}{|c|l|c|c|c|c|}
\hline \multirow{2}{*}{ Identificação } & \multicolumn{1}{|c|}{$\begin{array}{c}\text { Adaptação à } \\
\text { Família }\end{array}$} & \multicolumn{2}{|c|}{ Superproteção } & \multicolumn{2}{c|}{$\begin{array}{c}\text { Dificuldade com } \\
\text { aceitação do problema }\end{array}$} \\
\cline { 3 - 6 } & & Mãe & Pai & Mãe & Pai \\
\hline FCM & $\begin{array}{l}\text { Não houve adaptação. } \\
\text { Desagregou a família. }\end{array}$ & S & N & S & S \\
\hline MAP & $\begin{array}{l}\text { Sem dificuldades, embora } \\
\text { pai acha treinamento } \\
\text { inútil. }\end{array}$ & S & N & N & N \\
\hline MB & $\begin{array}{l}\text { Mãe procurou ajuda } \\
\text { psiquiátrica. }\end{array}$ & S & +- & S & N \\
\hline AAW & Sem dificuldades. & N & S & N & N \\
\hline CAFM & $\begin{array}{l}\text { Sem dificuldades na } \\
\text { adaptação (ciúmes da } \\
\text { irmã). }\end{array}$ & N & S & S & S \\
\hline ACPG & $\begin{array}{l}\text { Dificuldades de adaptação } \\
\text { à família. }\end{array}$ & S & N & S & S \\
\hline ECF & $\begin{array}{l}\text { Sem dificuldades na } \\
\text { adaptação. }\end{array}$ & N & N & N & N \\
\hline RAS & Adaptação à família. & S & S & N & N \\
\hline SMM & Difícil adaptação & S & S & S & S \\
\hline SRC & Adaptação à família. & S & N & S & N \\
\hline
\end{tabular}

$\mathbf{S}=\operatorname{sim} \mathbf{N}=$ não $\quad+-=$ mais ou menos $\mathbf{a}=$ anos $\mathbf{m}=$ meses 
Parece evidente que quando o treinamento e iniciado tardiamente, como o caso SRC, o desempenho da criança após treinamento, não alcança os níveis daqueles que tiveram oportunidade de estimulação mais precoce. Estes são os casos de SRC, ECF, AA W e ACPG.

A aceitação da criança no ambiente familiar foi fator importante para o seu bom desempenho, após estimulação (Tabela 4). Aparentemente MB, que iniciou o treinamento com apenas 2 meses, não conseguiu alcançar desempenho proporcional, talvez devido a problemas emocionais da mãe, que necessitava tratamento psiquiátrico por um quadro depressivo profundo. Este acontecimento parece ser compatível com a descrição de reações de não aceitação do filho com a Síndrome de Down e a tristeza crônica ${ }^{7}$.

A presença de cardiopatia não representou fator limitante para o desempenho da criança. FCM e MAP iniciaram estimulação precocemente e apesar de apresentarem cardiopatia congênita, tiveram bom desempenho depois de convenientemente estimulados.

ECF cardiopata, iniciou tardiamente o treinamento e como os outros que se apresentam tardiamente para a estimulação, não apresentou resultado proporcional ao tempo empregado para seu tratamento.

Crianças com Síndrome de Down criadas em famílias com numerosos filhos apresentam maior desempenho e adaptação mais fácil, quer sejam estimulados precocemente, quer o sejam tardiamente. Isto pode ser observado com MAP (10 filho), ECF e RAS (4 filho).

$\mathrm{O}$ aleitamento materno (SRC, CAFN) também favorece a adaptação da criança à família. $O$ caso $M B$, apesar de ter se beneficiado com aleitamento materno, não teve desempenho proporcional ao esperado devido a mãe de MB ser depressiva não permitia um entrosamento adequado e a formação do vínculo afetivo (bonding) durante a amamentação.

Durante a realização do presente trabalho, foi notado que certos fatores afetaram direta ou indiretamente os programas de assistência as crianças atípicas. Estes fatores são múltiplos e estão ligados ao nascimento, diagnóstico precoce, efetiva orientação e treinamento, educação, ambiente e sociedade, mas, acima de tudo, são estreitamente ligados aos seres humanos, suas atitudes, preconceitos, hábitos e costumes.

A primeira necessidade de um povo e de um indivíduo e aquela de uma força ativa e sensível, pela qual o homem é capaz de prosseguir, agir, combater e triunfar. Esta necessidade introduziu nas raças primitivas o atletismo e os exercícios e, baseados nisso, foram iniciados os primeiros passos na educação dos retardados, e a imitação destacou-se como um dos meios mais poderosos para se obter o progresso ${ }^{22}$. Esta imitação, na criança Down, não é um traço característico da síndrome, mas uma manifestação de sua infância prolongada $^{3}$. Isto porque o comportamento de imitação pode ser prontamente instituído através de estimulação sensorial e motora, pelo uso de vários brinquedos e jogos repetitivos simples. Na criança retardada esse comportamento não se desenvolve tão rapidamente quanto no normal; assim, um esforço mais concentrado e necessário nesta etapa, para sua efetiva ocorrencial ${ }^{1}$.

O presente trabalho desenvolveu-se totalmente baseado neste principio de imitação, 
desde o início até o final do treinamento. Com isto foram obtidos os resultados desejados quanto a linguagem, trabalhos caseiros e coordenação motora. Verificou-se também que, quanto maior é a quantidade de estímulos imitativos fornecidos à criança, mais rapidamente ela adquire as habilidades pretendidas.

Nenhuma criança atípica aqui estudada apresentou problemas de nascimento que pudessem influenciar em seu subseqüente desenvolvimento. A literatura tem mostrado que crianças nascidas com uma boa avaliação de Apgar (7 a 10), não apresentam dificuldades perinatais, estabelecem precocemente o seu contato com a mãe e iniciam o processo de empatia ("bonding") no inter-relacionamento mãe-filho. Crianças com baixo Apgar (0 a 6), são consideradas em risco de terem um agravamento do seu retardo mental por anormalidades neurológicas ${ }^{15}$, com conseqüente interrupção dos primeiros contatos com a mãe.

Estudos em animais, sobre o efeito de separação da mãe e filhote por curtos períodos, tem demonstrado conseqüências desastrosas, como rejeição e mesmo extermínio de sua cria. Supõe-se que os mesmos sentimentos podem ser experimentados pela mãe humana quando ela e seu filho são separados, devido a necessidade de cuidados especiais. Algumas mães levam mais tempo que outras para entrosar-se com seu nenê ${ }^{10}$ sendo assim, as mães que tiveram um contato íntimo imediato, mostraram um maior "attachment behavior" (comportamento de ligações afetivas). Ainda esse autor afirma que o próprio cheiro é muito importante, sabendo-se que o bebê pode discriminar entre o seio de sua própria mãe e o de outras mulheres, a partir do quinto dia de vida. Lavar o seio antes de amamentar e, então, não somente desnecessário, mas também pode remover alguma atração natural da criança pelo seio. A criança ao nascer, deve ser colocada imediatamente nos braços da mãe onde pode ser acariciada. A criança deve permanecer nua, sem ser lavada, em contato com os seios da mã $e^{10}$. Neste trabalho, algumas das mães relataram que o pior momento foi logo após o nascimento, quando o nenê foi carregado às pressas para o berçário, onde permaneceu até a alta hospitalar. Neste momento ela foi entregue aos braços da mãe e ambos foram despachados como se estivessem incomodando médicos e enfermeiras. Algumas receberam o diagnóstico da síndrome no hospital, mas não sabiam o que fazer com seu nenê, se poderiam dar-Ihe o seio ou não, pois além de apático ele era "mole" demais. Outras souberam do diagnóstico meses e até anos depois -"mesmo desconfiada, como ninguém tivesse falado nada, achava que tudo estava bem". Foi observada a importância do aleitamento materno deste ser atípico, não apenas como um meio de aproximar a mãe de seu filho e iniciar seu contato físico-mental, mas também como um meio de proteção e estímulo para seu desenvolvimento. As crianças que tiveram período mais longo de aleitamento materno apresentaram também melhor desempenho.

Nos casos (10) aqui estudados as crianças parcialmente amamentadas no seio materno (MB, CAFN e SRC), com suplementação, e as totalmente amamentadas na mamadeira (AAW, ACPG e SMM) apresentaram infecções gastro-intestinais, infecções de ouvido, 
obesidade, problemas com a dentição, caries e alergias, que embora comuns em crianças Down, foram reduzidas ou ausentes naquelas totalmente amamentadas no seio materno por mais de 3 meses. O maior problema envolvido com o aleitamento materno parece ser a rotina hospitalar, que da suplementação para aquietar a criança entre as amamentações, ou à noite, achando mais fácil dar mamadeira do que levar a criança para a mãe amamentá-la. Este problema tem sido evitado em hospitais que adotaram o sistema de alojamento conjunto.

A maior queixa encontrada entre muitas das mães, quando entrevistadas, foi a falta de informações, ou o diagnóstico tardio. Muitas delas descobriram o problema do filho, através de amigos, vizinhos, na rua ou em uma visita ao pediatra, devido a outro problema qualquer, mas raramente no hospital, precocemente, após o parto.

Algumas autoras ${ }^{11,12}$ questionaram justamente a falta de informações iniciais adequadas, bem como o atraso em dizer que a criança tem síndrome de Down. Eles relatam que os pais dessas crianças sentem que são abandonadas justamente quando é mais necessária a ajuda para reagrupar os fragmentos das suas vidas.

Uma expressão facial, um olhar ou gesto entre médicos e enfermeira na sala de parto, é, muitas vezes, suficiente para que a mãe desconfie que algo está errado. Sem o aconselhamento genético adequado e reforços subseqüentes, os pais buscarão o culpado do problema, freqüentemente acusando-se um ao outro ou aos parentes próximos ou longínquos.

A falta de compreensão sobre a causa da Síndrome de Down pode gerar ansiedade em torno da vida sexual do casal e acabar afastando-os devido ao medo de gerar outras crianças iguais $^{4,12}$. De dez casos aqui estudados, três casais sofreram influências negativas dos avós das crianças. Os pais dessas crianças envolveram-se em relacionamentos extraconjugais, com a conseqüente deterioração dos seus casamentos e lares. A literatura cita que especialmente os avós, freqüentemente, não crêem na inevitabilidade da deficiência mental $^{12}$. Em nosso estudo de 10 famílias foram constatados também os mesmos aspectos (avós de FCM e SMM).

Apesar das conquistas marcantes ocorridas na medicina durante os anos recentes, muitas pessoas ainda ignoram que a Síndrome de Down é um defeito genético, e portanto, incurável. $O$ fato de todas as crianças do presente estudo apresentarem trissomia por não disjunção representa, entretanto, um alívio, pois o risco de repetição é baixo e o aconselhamento genético mais simples. Quando a excepcionalidade da criança não era aceita (FCM, CAFN, ACPG e SMM), ocorria a demora nas fases de desenvolvimento e piorava o estado geral de saúde da criança. Freqüentemente a falta de experiência em cuidados básicos com crianças, especialmente em mães jovens, provoca não somente problemas entre o casal, mas também foi responsável pelo progresso excepcionalmente lento no desenvolvimento dos filhos Down ${ }^{4,5,6}$. Na presente pesquisa, isto também foi observado em 6 dos casos (FCM, MB, ACPG, SMM, CAFN e AA W) estudados, acontecendo o mesmo desenvolvimento lento nas crianças onde existia uma superproteção por parte de um ou mais membros da família, talvez devido as dificuldades na aceitação do problema. 
Já nos casos em que os pais foram atendidos logo após o nascimento da criança atípica e receberam orientações sobre a síndrome de Down, sobre o seu possível desenvolvimento, sobre o prognóstico médio em termos de expectativa de vida e como lidar com um ser atípico observamos que a ansiedade do casal diminuiu significativamente (FCM, MAP, MB e SMM).

A literatura especifica reforça a importância de explicar em linguagem simples o processo pelo qual a criança Down é gerada e os problemas associados com seu desenvolvimento intra e extra-uterino, salientando que a Síndrome foi devido à uma aberração cromossômica (problema genético) ${ }^{4,6}$.

Em segundo lugar o autor acredita que, dadas aos pais orientações práticas e regulares sobre alimentação, cuidados especiais e gerais e estimulação, suas atitudes de desespero poderiam ser convertidas em ações positivas e construtivas.

Foi citado por vários autores ${ }^{4,21}$ a importância em se conseguir a confiança dos pais e a necessidade de existir completa honestidade nas entrevistas, principalmente a primeira, na qual os pais são familiarizados com o problema do seu filho. O profissional deve ser honesto ao revelar o diagnóstico, prognóstico e etiologia do mal em questão.

Nos 10 casos aqui estudados, embora os pais se encontrassem em fase particularmente vulnerável após o aconselhamento genético, e muitos deles chegassem ao serviço de orientação angustiados, na esperança de ouvir que tudo não passava de um "terrível engano", nenhum fato durante a entrevista foi omitido, ou reduzido em "meias verdades", para acalmar o casal, pois é de suma importância que o orientador não alimente falsas ilusões, que futuramente trarão uma decepção major.

É evidente que nenhuma previsão sobre os níveis de desempenho ou sobre a idade mental máxima pode ser feita, mas, no caso da Síndrome de Down, há padrões desenvolvimentais bem descritos. Isto favorece uma aproximação das condições medias, em termos de desenvolvimento, para que os pais possam ter uma idéia, embora não exata, do futuro do seu filho.

Os primeiros anos do Down não diferem tanto de um bebê "normal" exceto nos principais estágios desenvolvimentais, que ocorrem um pouco mais tarde. Entretanto, a criança responderá a atenção como qualquer outro bebê e a ansiedade e tensão são facilmente transmitidos a criança e produzem sinais de inquietude e frustração ${ }^{3}$.

O trabalho executa do com as dez famílias estudadas visou não apenas a orientação e ao apoio durante os períodos de crise, mas a estimulação precoce para melhorar a curiosidade do recém-nascido ou criança; as áreas auditivas, gustativas, olfativas e visuais; propiciar a criança o desenvolvimento das áreas sensoriais e motoras, melhorando assim coordenação, percepção, senso tátil. Além disso, as áreas de hábitos da vida daria e social, ou seja, habilidades básicas de sobrevivência, foram estimuladas e aperfeiçoadas, por exemplo: alimentar-se sozinho, tomar banho.

O papel da enfermagem e ensinar a família como melhor ajudar seu filho a progredir. Ela deve elaborar programas de treinamento, semanalmente, para os pais executarem em 
casa. Avaliação continua e anotações do progresso alcançado, permitem que a mãe e a enfermeira planejem objetivos e métodos de ensino a serem atingidos em curto prazo". A enfermeira pode ajudar a mãe no treinamento e motivação da criança retardada, e tanto a criança quanto a mãe se beneficiarão de entrevistas de orientação regulares ${ }^{13}$. 0 processo de enfermagem dirigido a assistência as famílias com crianças retardadas envolve um processo que resulta em mudança. $\mathrm{Na}$ área de retardamento mental este processo é dirigido para a assistência aos pais, e a promoção e manutenção do funcionamento independente da criança que tem atraso no desenvolvimento ${ }^{1}$.

A enfermeira precisa desenvolver uma abordagem sistemática e planejar intervenções nos cuidados do recém nascido e criança mentalmente retardada. O objetivo final do processo é modificar o ambiente para aprendizagem e gerar comportamentos mais independentes na criança. É extremamente importante também assegurar que a nenhuma criança com a Síndrome de Down se permita perder os primeiros anos de vida e o potencial que tem ao nascer, ajudando a desenvolver seus talentos ao máximo, quaisquer que sejam, e remover onde possível o preconceito que tem existido por tanto tempo em tomo dessas crianças ${ }^{4,6}$.

Em suma, o que é de mais relevância no presente trabalho, é o campo de ação da enfermeira, que tem sido pouco explorado (até presente data apesar de serem conhecidos vários trabalhos nos Estados Unidos em particular um trabalho desenvolvido por enfermeiras em Washington, São Francisco e Berkley ${ }^{1}$; trabalhar com tais famílias, com um enfoque preventivo, é gratificante e produz resultados às vezes, além da expectativa, como foi observado nos casos (MAP, MB, AAW, CAFN, ECF, RAS, ACPG, SMM e SRC)).

Há necessidade de assistência às famílias o mais precocemente possível. Qualquer programa que vise apenas a estimulação da criança está condenado a falhar, pois a assistência precisa ser global a família.

No seu livro KRINSKI ${ }^{16}$ salienta quatro das noventa e cinco recomendações do Painel Kennedy (1962) em relação aos programas de assistência integral ao retardado mental:

a) planejamento de serviços para deficientes mentais: a ênfase sendo dada no treinamento de aquisição de um emprego que o tome útil a si e a sociedade;

b) pesquisar o potencial de trabalho de cada deficiente mental afim de que sejam aproveitadas ao máximo suas aptidões, habilidades e interesses;

c) serviços para a efetivação de tais programas devem ser organizados o mais cedo possível

e mantidos durante o tempo em que for necessário;

d) esclarecer a comunidade sobre os diferentes aspectos do problema. Incentivar a comunidade e requerer do governo a elaboração de programas de estimulação e reabilitação.

Para que essas recomendações sejam implantadas no Brasil, será necessária a formação de uma equipe multidisciplinar, na qual a enfermeira pode ter o papel de orientaçãoprogramação, e que venham a se tornar um ponto de apoio para a família. Tal equipe deveria ser ligada a serviços de saúde (hospitalar, de saúde pública e saúde mental), para que uma 
ação mais ampla seja atingida e maior extensão da população seja beneficiada.

\section{Considerações Finais}

01. O próprio nascimento da criança influencia o seu desenvolvimento subseqüente (um bom Apgar; oxigenação adequada e bom aquecimento para cobrir as deficiências do controle termoregulador);

02. A criança atípica não difere da normal quando responde a atenção e carinho (despertando curiosidade), e sua aprendizagem e desenvolvimento seguem quase passo por passo a escala normal;

03. O ensino e reforço na criança com a Síndrome de Down estimulam a imitação através do qual ela vai aprender;

04. As crianças que foram amamentadas no seio materno pelo menos até 3 meses se desenvolveram melhor e apresentam menos problemas de saúde, favorecendo também "bonding" entre mãe e filho;

05. A estimulação precoce favorece o desenvolvimento da criança atípica. Levando-se em consideração também a favorabilidade do ambiente (problemas do casal, casamento em crise e medos, refletem no filho). Quando o diagnóstico é evidente ao nascer deve se iniciar a estimulação precoce ainda no berçário e orientação da mãe quando ainda internada na maternidade, facilitando assim uma assistência eficaz;

06. Estimular a independência da criança ensinando hábitos básicos de sobrevivência: comer sozinha, tomar banho, vestir-se, entre outros;

07. Devido a falta de orientação precoce, principalmente em casais jovens houve deterioração

do casamento, medos associados com a origem do ser atípico na família;

08. As mães jovens que apresentam falta de experiência aos cuidados básicos e gerais da criança apresentaram problemas de relacionamento no casal que foi responsável pela passagem lenta nas diferentes fases de desenvolvimento com piora do estado geral de saúde da criança;

09. A não aceitação da criança atípica com subseqüente superproteção deturpa o desenvolvimento da criança;

10. A busca pelos pais de falsas ilusões em relação ao problema da criança atípica; eles esperam ouvir a existência do problema ser negada. Uma orientação adequada diminui-Ihes a ansiedade;

11. Os avôs têm participação importante no desenvolvimento da criança e apoio do casal. É importante a orientação deles sobre o problema genético e incurável da Síndrome de Down;

12. Programas de treinamento para serem executados pelos pais em casa, quando realizados regularmente, levam a bons resultados; em caso contrário, a estimulação é um fracasso; 
13. O papel da enfermeira é provocar mudanças, planejar uma intervenção sistematizada junto à família e desenvolver programas de treinamento a serem avaliados continua mente. Deve apoiar a família durante a crise inicial, ajudando-a a atravessá-la sem o núcleo familiar se desagregar; e

14. É necessário trabalhar com a família como um todo, incluindo avós, filhos normais do casal e outros membros chave para conseguir êxito na estimulação da criança.

Diagnosis of Down Syndrome can be made in the nursery. The presence of an atypical child often leads to desegregation of the family. Nursing intervention teaching early stimulation, hygiene and feeding techniques permits better adjustment.

The study of 10 Down Syndrome children and their families during o period of 6 years, made it possible to show that immediate diagnosis of the defect leading to early stimulation of the child and counseling of the couple led to more favorable results. Later stimulation was found to cause a more difficult adaptation of the child within the family.

UNITERMS: Atypical child, atypical, perform, bonding, Down Syndrome.

El diagnóstico de Síndrome de Down puede ser realizado en la nursery, la presencia de este niño atípica lleva a conflictos familiares. La intervención de enfermería, enseñando técnicas higiénicas, alimentarías y de estimulación precoz podría, permitir una adecuación familiar mejor.

El estudio de 10 niños con Síndrome de Down y sus familiares realizado en 6 años demostró que el diagnóstico precoz de la afección permite que se inicie precozmente la estimulación de niño, así como la orientación del matrimonio. La estimulación tardía lleva a resultados menos favorables, así como hay mayor dificultad de adaptación de 10 niño a su familia.

UNITERMOS: Niño atípico, atípica, desempeñar, vínculo afectivo.

\section{REFERÊNCIAS BIBLIOGRÁFICAS}

01. BARNARD, K.E., POWELL, M. L. Teaching the mentally retarded child a family care approach. Saint Louis: C.V. Mosby,1972.

02. BAYLEY, N. Bayley scales or infant development. New York: The Psychological Corporation, 1969. 
03. BENDA, C. E. Down's Syndrome: mongolism and its management. New York: Grune \& Stratton, 1969.

04. BRINKWORTH, R. Care and training for the baby with Down's Syndrome. Birmingham, Inglaterra: Down's Babies Association, 1973.

05. BRINKWORTH, R., COLLINS, J. Improving babies with Down's Syndrome and introducing them to school. Newcastle: Mourner Observer Press, 1973.

06. BRINKWORTH, R. Early training for the infant with Down's Syndrome. Birmingham: Down's babies Association, 1974.

07. DAMROSCH, S. P., PERRY, LA. Self-resported adjustment, chronic sorrow and coping of parents of children with Down Syndrome. Nurs.Res., U.SA, v. 38, n. 1, p. 25-30, 1989.

08. Down, J. H. Observation on an ethnic classification of idiots. Clinical lectures and reports of the London Hospital, Londres, v. 3, p. 259-262, 1866.

09. EVANS, K. What hope for Hannah? Nurs.Times, Londres, v. 86, n. 47, p. 58-9, 1990.

10. JOLLY, H. The importance of bonding for the newborn baby, mother and father. Nurs.Mirror, Londres, v. 147, n. 9, p. 19-21, 1978.

11. JONES, M. E. O. et al. Teaching the parents to help the child. Nurs.Mirror, Londres, v. 148, n. 21, p. 26-7, may 1979.

12. JOUSTRA, M. Down, but not out. Nurs.Mirror, Londres, v. 152, n.1, p. 25-26, 1981.

13. KALKMAN, M. E. Recognizing. AmJ.Nurs., v. 68, n. 3, p. 536-9, march 1968.

14. KOONTZ, C. Koontz child development program: training activities for the first 48 months. New York: Westerns Psychological Services, 1974.

15. KOLPEMAN, B. Recém nascido de alto risco. São Paulo, Escola Paulista de Medicina, 1974. (Mimeografado). (Apostila do Dept ${ }^{\circ}$ de Pediatria - EPM).

16. KRYNSKI, S. et al. Deficiência mental. Rio de Janeiro: Atheneu, 1969. 
17. LEJEUNE, J., TURPIN, R., GAUTIER, M. Le mongolisme, premier exemple d'aberratim autosomique humaine. Ann. Genet., Paris, v. 1, n. 41, 1959.

18. MICHELE, J.L. Estudo citogenético de recém-nascidos selecionados nascidos no Hospital das Clínicas de Ribeirão Preto. Ribeirão Preto, 90 p. Tese (Doutorado) departamento de Genética da Faculdade de Medicina de Ribeirão Preto, Universidade de São Paulo, 1980.

19. POLANI, P. E., BRIGGS, J.H., FORD, C. E. A mongol girl with 45 chromosomes. Lancet., Londres, v. 1, p. 721-4, 1969.

20. PROGRAMA DE ESTIMULAÇÃo PARA CRIANÇA DE UM MÊS. Seção de Desenvolvimento da Criança. Washington, D. C.: Children's Hospital of Washington, 1967.

21. ROSS, A. The exceptional child in the family. New York: Grune \& Stratton, 1964.

22. SEGUIN, E. Origin of the treatment and training of idiots. ( $n$ : ROGEN, M. et al. The history or mental retardation, 1, Baltimore: Univ. Park Press, 1976.

23. UZGIRIS, H. Training assessment: the construction of object relations in space. EEUU: 1975. (Scale IV). (Mimeografado).

24. UZGIRIS, H. Training assessment: the development of operational causality. EEUU: 1975. (Scale V). (Mimeografado).

25. VULPE, S. Home care and management or the mentally retarded child. Toronto: National Institute of Mental Retardation. Canadian Association for the Mentally Retarded, 1969.

26. XAVIER, A. R. Estudo da incidência, prevalência e características fenotípicas da Síndrome de Down na cidade de Ribeirão Preto. Ribeirão Preto. Dissertação (Mestrado) - Departamento de Medicina Social da Faculdade de Medicina de Ribeirão Preto, Universidade de São Paulo, 1974. 